\title{
Symptoms predicting psychosocial impairment in bulimia nervosa
}

Article

Accepted Version

Jenkins, P. E., Staniford, J. and Luck, A. (2018) Symptoms predicting psychosocial impairment in bulimia nervosa. Eating and Weight Disorders - Studies on Anorexia, Bulimia and Obesity, 23 (5). pp. 665-671. ISSN 1124-4909 doi: https://doi.org/10.1007/s40519-017-0397-6 Available at https://centaur.reading.ac.uk/76087/

It is advisable to refer to the publisher's version if you intend to cite from the work. See Guidance on citing.

To link to this article DOI: http://dx.doi.org/10.1007/s40519-017-0397-6

Publisher: Springer

All outputs in CentAUR are protected by Intellectual Property Rights law, including copyright law. Copyright and IPR is retained by the creators or other copyright holders. Terms and conditions for use of this material are defined in the End User Agreement.

\section{www.reading.ac.uk/centaur}

\section{CentAUR}

Central Archive at the University of Reading 
Reading's research outputs online 


\section{Symptoms predicting psychosocial impairment in bulimia nervosa}

Dr. Paul E. Jenkins ${ }^{a, b}$, Jessica Staniford ${ }^{a, c}$, Dr. Amy Luck ${ }^{c}$

${ }^{a}$ Cotswold House Eating Disorders Service, Oxford Health NHS Foundation Trust, Oxford, UK

bSchool of Psychology, University of Birmingham, UK

'Buckinghamshire Community Eating Disorders Service, Oxford Health NHS

Foundation Trust, Aylesbury, UK

\section{Corresponding author}

Paul E. Jenkins, D.Clin.Psychol.

Cotswold House Eating Disorders Service

Warneford Hospital

Oxford OX3 7JX

United Kingdom

Tel: +44 (0)1865 902315

Fax: +44 (0)1865 337417

E-mail:pej106@gmail.com 


\begin{abstract}
Purpose: The current study aimed to determine which particular eating disorder (ED) symptoms and related features, such as BMI and psychological distress, uniquely predict impairment in bulimia nervosa (BN). Methods: Two hundred and twenty-two adults with BN completed questionnaires assessing ED symptoms, general psychological distress, and psychosocial impairment. Regression analyses were used to determine predictors which account for variance in impairment. Results: Four variables emerged as significant predictors of psychosocial impairment: concerns with eating; concerns with weight and shape; dietary restraint; and general psychological distress. Conclusions: Findings support previous work highlighting the importance of weight and shape concerns in determining ED-related impairment. Other ED symptoms, notably dietary restraint and concerns with eating, were also significant predictors as was psychological distress. Results suggest that cognitive aspects of EDs, in addition to psychological distress, may be more important determinants of impairment than behavioural symptoms such as binge eating or purging.
\end{abstract}

Keywords: impairment; bulimia nervosa; predictors; weight and shape concerns 


\section{Symptoms predicting psychosocial impairment in bulimia nervosa}

\section{Introduction}

Eating disorders (EDs) are associated with significant impairment in psychological functioning, social functioning, and physical health [1]. Greater knowledge of this relationship has important implications for understanding both treatment-seeking and diagnosis $[2,3]$.

Existing studies have investigated the relationship between ED symptoms and subsequent impairment (i.e., the impact on functioning; [4]), as well as related constructs such as health-related quality of life (HRQoL), to which impairment contributes (e.g., see [5]). More 'cognitive' ED symptoms (such as over-concern with eating, weight, shape, and their control) have been more consistently associated with impairments in psychological and social functioning than 'behavioural' symptoms, such as binge eating and vomiting [e.g., 6-8]. However, the majority of such work has been conducted with nonclinical samples [3], leaving gaps in our knowledge regarding predictors of impairment in clinical populations, specifically regarding those ED symptoms most associated with psychosocial impairment occurring at clinically significant levels.

Two recent longitudinal studies $[9,10]$ have, however, looked at predictors of psychosocial impairment in individuals who received treatment for an ED. Martín et al. [9] found that "more abnormal attitudes and behaviors associated with ED" were related to greater impairment (p. 165). Their use of three subscales ('dieting', 'bulimia' and 'oral control') of a larger measure [11] (see also [12]) did not allow for assessment of the predictive effect of distinct behaviours, such as binge eating or 
self-induced vomiting. Similar findings were reported by Davidsen et al. [10], who found a strong association between eating psychopathology and functional impairment across three domains (work/school, social life/leisure, and family life/home responsibilities) in 159 patients participating in a treatment study on group psychotherapy for EDs.

Considering the literature as a whole, some consistent associations between ED symptoms and impairment have emerged. Reliable predictors include aspects of body image (such as weight and shape concerns) and dietary restriction, but purging and binge eating have been less consistently associated [3,8,13,14]. Latner et al. [8] highlight, for example, that this is in line with previous studies linking more 'cognitive' symptoms (such as body image) with quality of life and functional impairment reported by patients with EDs (e.g., [6]). However, an alternative explanation could be that behavioural symptoms were less common in these samples. A study of 53 women in outpatient treatment, on a waiting list for treatment, or recently discharged from treatment [15] found an association between ED behaviours (binge eating, dietary restriction, laxative use, and self-induced vomiting) and HRQoL but did not control for depression (rather, using this as an outcome variable). More recently, a number of authors have emphasised the importance of measuring and controlling for psychological distress, a concept linked closely to depression [16], when considering the relationship between ED symptoms and psychosocial impairment $[8,10]$.

Furthermore, different measures have also been used across studies, with few using an ED-specific measure of impairment (cf. [9]) and more using generic measures of HRQoL, such as instruments from the 'SF family' of measures (see [17]).

Investigation of predictors of psychosocial impairment in individuals with specific EDs is key in understanding more about each illness, and also allows for detailed study of 
a number of core symptoms that are common to all individuals with that diagnosis. In the case of bulimia nervosa (BN), core symptoms are defined as weight and shape concerns, binge eating, and compensatory weight control behaviours (such as self-induced vomiting and dietary restriction) [18]. The current study therefore aims to investigate how symptoms of BN contribute to impairment, incorporating the most recent findings in this area. Based on previous work (e.g., $[10,13,15,19])$, it is also important to control for other variables (such as age, gender, and psychological distress) that may be related to impairment, and to investigate whether specific ED symptoms explain variance in impairment over and above these variables.

\section{Material and Methods}

Participants

Participants were referred to one of two regional ED services in the UK over the period between February 2012 and April 2016. The two services, provided by the same NHS Trust, cover a population of approximately one million adults aged above $171 / 2$ (there is no upper age limited). In line with service trends, the majority of referrals (approximately 80\%) were made by general practitioners, with the remainder from other mental health services, such as general psychiatric services. As individuals are referred for specialist assessment and treatment of an ED, it could be anticipated that most will report significant ED symptoms and associated impairment.

Participants were sent self-report questionnaires in advance of an appointment where diagnoses were made following clinical interview with a qualified mental 
health professional (e.g., clinical psychologist, counselling psychologist, psychiatrist, clinical nurse specialist). Participants provided information on symptoms in response to questions based on current diagnostic criteria [18], and diagnoses were subsequently discussed and agreed upon at multidisciplinary meetings. However, no formal diagnostic interview (e.g., EDA-5; [20]) is administered as part of the assessment.

Two hundred and thirty-four individuals were considered for the study, a number of whom were included in a previous study of BN severity [21]. However, a small proportion of individuals ( $\mathrm{n}=12$, all female) were recorded as having a body mass index (BMI) below 18.5, considered to be underweight $[20,22]$. Although diagnoses were established through detailed clinical interview and with reference to established diagnostic criteria [18], it was not possible in this study to confirm the diagnoses made and these individuals were therefore excluded from analysis. The total sample of 222 individuals ( $n=210$ females; $94.6 \%$ ) thus had BMls ranging from 18.5 to 40.6 $($ mean $=23.61, S D=4.57)$. Ages ranged from $17 \frac{1}{1} 2$ to 67 years $($ mean $=28.0, S D=$ 9.7) and all participants met criteria for full-syndrome BN according to DSM-5 criteria [18]. Duration of illness was available for 173 individuals and ranged from $<1$ year to 50 years $($ mean $=10.11, S D=9.72)$. Regarding symptom severity [18; see also 21 , data were available on 212 individuals. Of these, 99 were of Mild severity (46.7\%), 73 Moderate (34.4\%), 32 Severe (15.1\%), and 8 Extreme (3.8\%).

Data for the study were collected as part of routine care and the local NHS Trust Research and Development department granted permission for the study, noting that further NHS Research Ethics Committee approval was not required.

\section{Measures}


The Eating Disorder Examination - Questionnaire (EDE-Q; [23]) is a 36-item measure of eating pathology that assesses behavioural and cognitive symptoms over the previous 28 days. It has shown good psychometric properties (see [24]) and can generate a number of behavioural indices (such as frequency of selfinduced vomiting and objective binge-eating episodes; OBEs, defined as episodes of eating where a loss of control is experienced when consuming an unusually large amount of food) as well as four subscales (Restraint, Eating Concern, Shape Concern, Weight Concern). Subscales are rated on a $0-6$ scale, with higher scores indicating greater symptomatology. Due to high correlations $(r=.80)$ between the subscales of Shape Concern and Weight Concern, a composite 'Weight/Shape Concern' subscale was constructed from the mean of all 12 items. Cronbach's $\alpha$ in the current sample were as follows: Restraint, .73; Eating Concern, .67; Weight / Shape Concern, .87 .

The Clinical Impairment Assessment questionnaire (CIA; [25]) assesses severity of psychosocial impairment resulting from ED symptoms over the last 28 days. The measure has shown good psychometric properties in similar samples [26], and the 16 items are rated on a $0-3$ scale. A cut-off score of 16 has been suggested to indicate clinically significant impairment ([2]; see also [27]). Cronbach's $\alpha$ for the Total score was 89 .

The Clinical Outcomes in Routine Evaluation - Outcome Measure (CORE-OM; [16]) provides a measure of general psychological distress obtained through 34 items assessing symptoms experienced over the previous week. Items are scored from 0 -4 and provide a Total score, calculated as the mean of all items multiplied by 10 to aid interpretation (e.g., [28]). A cut-off score of 10 has been suggested to discriminate between clinical and general population samples [28], and evidence for 
its utility in the study of eating pathology has been demonstrated [29]. Cronbach's $\alpha$ was .94.

\section{Statistical analysis}

A two-step hierarchical regression analysis was planned. In the first step, four possible confounds (BMI, gender, age, CORE-OM Total score) were entered, followed by eight dichotomised predictor variables (OBEs, self-induced vomiting, laxative use, excessive exercise, Restraint, Eating Concern, Weight/Shape Concern, and extreme dietary restriction; see below). Of note, a distinction was made between dietary restraint, a more 'cognitive' aspect of attempting to restrict what one eats, and extreme dietary restriction, which describes going for long periods without eating [30]; both are assessed by the EDE-Q (see below). A power calculation [31] suggested a minimum $\mathrm{N}$ of 228 for a small-medium effect size $\left(f^{2}=0.08\right)$ at $p<0.05$, with a power of 0.8. The Durbin-Watson test (statistic $=2.044)$ satisfied the assumption of independence of errors, and both tolerances and variance inflation factors (VIF) were inspected (.706 $\leq$ tolerances $\leq .992 ; 1.008 \leq \mathrm{VIF} \leq 1.416)$, additionally suggesting no serious problem with multicollinearity. Missing data were excluded listwise, with a total sample of 196 datasets sufficient for regression analyses.

One outlier was identified (standard residual score $>3$ ) but was retained as rerunning analyses with this case deleted did not markedly change any of the findings, although collinearity statistics were marginally improved. The procedure was similar to that of an existing study of adolescents with EDs [14], whereby 'dummy variables' were created based on participants' responses on the EDE-Q. In part, this method was chosen due to the current study's focus on the association between 
diagnostically significant symptoms and impairment, rather than addressing the spectrum of eating disturbance (e.g., [8]), but also due to skewness and kurtosis in the distribution of most variables of interest. For frequency of OBEs, self-induced vomiting, and laxative use, these variables were coded as 1 when the behaviour was present at least weekly (over the last 28 days) and 0 when it was not, in line with diagnostic criteria [18]. Excessive exercise was coded as present if it was reported at least five times per week [8,32]. Dietary Restraint, Eating Concern, and Weight/Shape Concern, as measured by the EDE-Q, were coded as present if the mean score was at least 4 (e.g., $[8,33,34])$. A measure of extreme dietary restriction was included through use of a question on the EDE-Q assessing this, coded as present if meeting the frequency criterion of 3 or more times per week (e.g., [35]). Prevalence of these symptoms is reported in Table 1.

Table 1. Frequency (\%) of symptoms in the current study (see text for demographic information)

\begin{tabular}{llc}
\hline Variable & N & Frequency, n (\%) \\
\hline OBEs $^{\mathrm{a}}$ (at least weekly) & 216 & $190(88.0)$ \\
Self-induced vomiting (at least weekly) & 211 & $167(79.1)$ \\
Laxative use (at least weekly) & 213 & $54(25.4)$ \\
Excessive exercise (at least 5 times per week) & 212 & $43(20.3)$ \\
Restraint (score $\geq 4)$ & 222 & $125(56.3)$ \\
Eating Concern (score $\geq 4)$ & 222 & $150(67.6)$ \\
Weight/Shape Concern (score $\geq 4)$ & 222 & $187(84.2)$ \\
Extreme dietary restriction (at least 3 times per week) & 222 & $47(21.2)$ \\
\hline
\end{tabular}


$\mathrm{CIA}^{\mathrm{b}}$ score $\geq 16$

CORE-OMc score $\geq 10$
222

222
$218(98.2)$

207 (93.2)

${ }^{\mathrm{a} O B E s}=$ objective binge-eating episodes; ${ }^{\mathrm{b}} \mathrm{CIA}=$ Clinical Impairment Assessment questionnaire; ' $\mathrm{CORE}-\mathrm{OM}=$ Clinical Outcomes in Routine Evaluation - Outcome Measure

\section{Results}

Over $98 \%$ of individuals scored above 16 on the CIA, suggesting a sample experiencing significant impairment from ED symptoms. Similarly, over $93 \%$ scored above the suggested cut-off on the CORE-OM, indicating a sample with widespread clinical levels of distress. The first step of regression analyses accounted for $46.7 \%$ of the variance in CIA Total scores $(F(4,191)=41.792, p<0.001)$. CORE-OM Total score was a significant predictor but not BMI, gender, or age. In the second step, inclusion of additional predictors was associated with a significant increase in total variance accounted for $\left(\Delta \mathrm{R}^{2}=11.4 \%, F(8,183)=6.217, p<0.001\right)$. As detailed in Table 2 only CORE-OM Total scores (which remained significant), Dietary Restraint, Eating Concern, and Weight/Shape Concern were significant predictors of CIA scores. 
Table 2. Results of regression analyses of variables predicting CIA Total scores (N $=196)$

\begin{tabular}{llllll}
\hline Variable & $\mathrm{B}$ & $\mathrm{SE}$ & $\beta$ & $\mathrm{t}$ & $\mathrm{p}$ \\
\hline Step 1 & & & & & \\
$\quad$ Constant & 18.453 & 3.566 & - & 5.174 & $<0.001$ \\
BMI $^{\mathrm{a}}$ & 0.040 & 0.108 & 0.021 & 0.374 & 0.71 \\
Gender & -2.713 & 2.208 & -0.065 & -1.229 & 0.22 \\
Age & 0.006 & 0.052 & 0.006 & 0.114 & 0.91 \\
CORE-OM & & & & & \\
Total & $\mathbf{0 . 8 6 2}$ & $\mathbf{0 . 0 6 8}$ & $\mathbf{0 . 6 8 2}$ & $\mathbf{1 2 . 7 5 5}$ & $<\mathbf{0 . 0 0 1}$
\end{tabular}

Step 2

\begin{tabular}{llllll} 
Constant & 15.189 & 3.528 & - & 4.305 & $<0.001$ \\
BMI $^{\mathrm{a}}$ & -0.029 & 0.104 & -0.015 & -0.278 & 0.78 \\
Gender & -2.431 & 2.041 & -0.058 & -1.191 & 0.24 \\
Age & 0.016 & 0.048 & 0.017 & 0.329 & 0.74 \\
CORE-OM $^{\mathrm{b}}$ Total & $\mathbf{0 . 6 6 9}$ & $\mathbf{0 . 0 7 1}$ & $\mathbf{0 . 5 2 9}$ & $\mathbf{9 . 4 0 3}$ & $<\mathbf{0 . 0 0 1}$ \\
OBEs $^{\mathrm{c}}$ & 2.147 & 1.346 & 0.082 & 1.596 & 0.11 \\
Self-induced vomiting & -0.345 & 1.032 & -0.017 & -0.334 & 0.74 \\
Laxative use & 0.148 & 1.040 & 0.007 & 0.143 & 0.89 \\
Excessive exercise & -0.350 & 1.070 & -0.016 & -0.327 & 0.74 \\
Dietary restraint & $\mathbf{2 . 3 2 1}$ & $\mathbf{1 . 0 0 1}$ & $\mathbf{0 . 1 3 2}$ & $\mathbf{2 . 3 1 8}$ & $\mathbf{0 . 0 2}$ \\
Eating Concern & $\mathbf{3 . 8 3 6}$ & $\mathbf{1 . 0 1 3}$ & $\mathbf{0 . 2 0 9}$ & $\mathbf{3 . 7 8 6}$ & $<\mathbf{0 . 0 0 1}$ \\
Weight/Shape Concern & $\mathbf{3 . 6 8 3}$ & $\mathbf{1 . 2 8 3}$ & $\mathbf{0 . 1 5 8}$ & $\mathbf{2 . 8 7 1}$ & $\mathbf{0 . 0 0 5}$ \\
Extreme dietary restriction & -1.217 & 1.152 & -0.056 & -1.057 & 0.29 \\
\hline
\end{tabular}

${ }^{\mathrm{a} B M I}=$ body mass index; ${ }^{\mathrm{b} C O R E-O M}=$ Clinical Outcomes in Routine Evaluation Outcome Measure; ' $\mathrm{OBEs}=$ objective binge-eating episodes 


\section{Discussion}

This was one of the largest studies looking at predictors of psychosocial impairment in EDs, and the first to use a sample comprised only of adults with BN. It found that, while a number of symptoms were associated with psychosocial impairment, only four remained as significant predictors when others were held constant. The first of these was a measure of general psychological distress, highlighting, firstly, the importance of using a measure of distress in such studies $[8,10]$ and, secondly, that ED concerns remain significant when this is controlled for [36]. An interesting question relates to whether a measure of psychological distress predicts variance over and above symptoms such as anxiety and depression and this might be a goal of further studies. Furthermore, use of disease-specific symptom measures may have been useful given the overlap with psychological distress and that these constructs are strongly correlated (e.g., see [10]).

The study found that important predictors of impairment included concerns around eating, weight, and shape, considered integral to the presentation of EDs (e.g., [30]). Results from the current study suggest that addition of these variables explains variance over and above psychological distress alone. Weight and shape concerns have been identified as reliable predictors of psychosocial impairment in previous studies (e.g., $[6,13,33,36,37])$ and thus results presented here offer further support to the conclusion of Latner et al. [8], who argue that this variable "may be paramount" (p. 596) in determination of impairment resulting from ED symptoms. The finding that eating concerns were a significant predictor of variance - in addition to weight and shape concerns - is in line with the findings of Mond et al. [33] who studied this in a large community sample of women, using a measure of HRQoL. They found that, when controlling for age and BMI, binge eating, dietary restriction, and eating 
concerns "showed small but statistically significant associations with increased impairment, whereas extreme concerns about weight or shape showed a very strong association" (p. 463). These findings have also been partially supported by longitudinal studies (e.g., $[9,10])$.

Regarding dietary restraint and restriction, findings are perhaps more equivocal. In a community-based study of 113 adults, Hovrud and De Young [13] found that the relationship between dietary restriction and psychosocial impairment was no longer significant when controlling for depression, leading the authors to conclude that "the relationship between restrictive eating and impairment is accounted for by gender, age, and/or depression" (p. 105). The current study used different measures, including both dietary restraint and extreme dietary restriction (and no measure of depression per se), but cannot reach the same conclusion, finding that only dietary restraint remained a significant predictor of impairment, at odds with some existing studies including both measures (e.g., [8]). These conflicting findings may be explained by these two measures assessing similar constructs or the use of different measures of impairment, but may also reflect the different samples used.

Despite these differences, some correspondence was observed between the current study and that of Hovrud and De Young [13], with similar methodologies and constructs assessed and both employing the CIA as the dependent measure. Both studies proposed models that explained similar amounts of variance in CIA scores, suggesting reliable findings; beta values for weight and shape concerns were similar ( 0.25 in [13], and 0.16 in the current study), with $58.6 \%$ and $58.1 \%$ of variance explained respectively. Regarding another aim of the study, results suggest that ED behaviours, such as binge eating, purging, and compensatory exercise, are not uniquely predictive of impairment when other symptoms such as weight and shape 
concerns are accounted for (see also [36]). However, some studies on community samples in particular have found statistical relationships with HRQoL, a similar but not identical construct (e.g., [37,38]), and the study of Hovrud and De Young did find an association between binge eating and psychosocial impairment. This apparent contradiction might represent different features of community or clinical samples, or could be related to the methods and measures used (which differed across studies). This finding does require replication as it suggests that individuals in the community may find behavioural symptoms, such as binge eating and purging, more impairing than those formally diagnosed with an ED [39]. An advantage of this study over previous work was the inclusion of discrete behaviours in the regression models, allowing for detailed analysis of predictors that were hypothesised based on previous work. However, data on duration of illness, which might represent an interesting variable to explore in the relationship between ED features and impairment, were available for only $78 \%$ of the sample and this was therefore excluded from analyses.

Possible under-reporting of binge eating (occurring at least weekly in only $88 \%$ of the sample) may have been due to shortcomings in the use of the EDE-Q. The measure focuses on the last 28 days (whereas diagnosis of $\mathrm{BN}$ concerns the last three months), and possible differences between interview and self-report have been highlighted, particularly relating to behavioural items, such as binge eating (e.g., [40]). Lack of a standardised diagnostic assessment was a shortcoming of the study, although all clinicians making diagnoses did so based on DSM criteria [18] and were very experienced in the treatment and assessment of eating disorders. Furthermore, as part of the study, scores on the EDE-Q were reviewed for consistency and agreement with interviewer reports. Despite a strength of using a measure designed for assessing psychosocial impairment directly resulting from ED 
symptoms [2], this is also a significant limitation of the study. It has been suggested that reliance on one measure of quality of life or impairment "is likely to be misleading" ([19], p. 177) and therefore an additional measure may have increased confidence in the findings reported here. Similarly, use of subscales of the EDE-Q reflected a broad assessment of body experience [41] and future studies might look in more detail regarding the influence of body image concerns on psychosocial impairment and HRQoL. Although a priori analyses were used, a small number of individuals were removed from the sample and this might have compromised statistical power. Participants in the study were drawn from referrals to a specialist unit and reported high levels of psychosocial impairment (e.g., see [26]). Findings must therefore be interpreted with this in mind, but support findings from existing literature conducted with non-clinical samples.

In conclusion, this study highlights the importance of dietary restraint, concerns about eating, weight, and shape and psychological distress in determining impairment resulting from eating pathology, findings that have emerged in previous work with other samples (e.g., $[8,10,14,33])$. Behavioural symptoms - specifically objective binge eating, self-induced vomiting, laxative use, excessive exercise, and dietary restriction - were not identified as significant predictors, suggesting that a "central cognitive disturbance" around eating, weight, and shape concerns ([42], p. 522) is a key correlate of impairment resulting from ED pathology. The findings presented here thus offer some indirect support for the cognitive-behavioural theory that addressing an individual's behavioural symptoms (e.g., binge eating) should not form the sole basis of treatment; rather, dietary restraint and over-valuation of eating, shape, weight, and their control must be successfully treated to address clinically significant impairment [30,42]. 


\section{Compliance with Ethical Standards}

Funding: This study received no external funding.

Conflict of Interest: On behalf of all authors, the corresponding author states that there is no conflict of interest.

Ethical approval: Relevant ethical standards were considered in the conduct of this research, which was approved by the local NHS Trust Research and Development, who noted that further review was not required.

Informed consent: Informed consent was not sought as this study considered collation of retrospective, routinely-collected data. 


\section{References}

1. Jenkins PE, Hoste RR, Meyer C, Blissett JM (2011) Eating disorders and quality of life: a review of the literature. Clin Psychol Rev 31:113-21. doi: 10.1016/j.cpr.2010.08.003

2. Bohn K, Doll HA, Cooper Z, O'Connor M, Palmer RL, Fairburn CG (2008) The measurement of impairment due to eating disorder psychopathology. Behav Res Ther 46:1105-1110. doi:10.1016/j.brat.2008.06.012

3. Mond JM, Hay PJ, Rodgers B, Owen C, Mitchell J (2006) Correlates of the use of purging and non-purging methods of weight control in a community sample of women. Aust N Z J Psychiatry 40:136-142. doi:10.1111/j.14401614.2006.01760.x

4. Ikeda E, Hinckson E, Krägeloh C (2014) Assessment of quality of life in children and youth with autism spectrum disorder: a critical review. Qual Life Res 23:1069-85. doi: 10.1007/s11136-013-0591-6

5. Wilson IB, Cleary PD (1995) Linking clinical variables with health-related quality of life. A conceptual model of patient outcomes. JAMA 273(1):59-65.

6. Lobera IJ, Ríos PB (2011) Body image quality of life in eating disorders. Patient Prefer Adherence 5:109-116. doi:10.2147/PPA.S17452

7. Vallance JK, Latner JD, Gleaves DH (2011) The relationship between eating disorder psychopathology and health-related quality of life within a community sample. Qual Life Res 20:675-682. doi:10.1007/s11136-010-9799-x

8. Latner JD, Mond JM, Vallance JK., Gleaves DH, Buckett G (2013) Quality of life impairment and the attitudinal and behavioral features of eating disorders. J NervMent Dis 201:592-597. doi:10.1097/NMD.0b013e3182982bbe 
9. Martín J, Padierna A, Unzurrunzaga A, González N, Berjano B, Quintana JM (2016) Predictors of change in psychosocial impairment secondary to an eating disorder. Psychiatry Res 243:161-167. doi:10.1016/j.psychres.2016.04.032

10. Davidsen AH, Hoyt WT, Poulsen S, Waaddegaard M, Lau M (2016) Eating disorder serverity and functional impairment: moderating effects of illness duration in a clinical sample. Eat Weight Disord doi:10.1007/s40519-0160319-z

11. Lavik NJ, Clausen SE, Pedersen W (1991) Eating behaviour, drug use, psychopathology and parental bonding in adolescents in Norway. Acta Psychiatr Scand 84:387-90.

12. Garner DM, Garfinkel PE (1979) The eating attitudes test: an index of the symptoms of anorexia nervosa. Psychol Med 9:273-9.

13. Hovrud L, De Young KP (2015) Unique contributions of individual eating disorder symptoms to eating disorder-related impairment. Eat Behav 18:103106. doi:10.1016/j.eatbeh.2015.05.001

14. Jenkins PE, Hoste RR, Celio Doyle A, Eddy K, Crosby RD, Hill L, Powers P, Mitchell JE, Le Grange D (2014) Health-related quality of life among adolescents with eating disorders. J Psychosom Res 76:1-5. doi:10.1016/j.jpsychores.2013.11.006

15. Latner JD, Vallance JK, Buckett G (2008) Health-related quality of life in women with eating disorders: association with subjective and objective binge eating. J ClinPsychol Med Settings 15:148-153. doi:10.1007/s10880-008$9111-1$ 
16. Barkham M, Margison F, Leach C, Lucock M, Mellor-Clark J, Evans C, Benson L, Connell J, Audin K, McGrath G (2001) Service profiling and outcomes benchmarking using the CORE-OM: toward practice-based evidence in the psychological therapies. J Consult ClinPsychol 69:184196. doi:10.1037/0022-006X.69.2.184

17. Turner-Bowker DM, Bartley PJ, Ware JE Jr (2002) SF-36® Health Survey \& “SF” Bibliography: Third Edition (1988-2000). QualityMetric Incorporated, Lincoln, RI.

18. American Psychiatric Association (2013) Diagnostic and statistical manual of mental disorders, 5th edn. American Psychiatric Publishing, Washington, DC.

19. Mond JM, Hay PJ, Rodgers B, Owen C, Beumont PJV (2005) Assessing quality of life in eating disorder patients. Qual Life Res 14:171-178. doi:10.1007/s11136-004-2657-y

20. Sysko R, Glasofer DR, Hildebrandt T, Klimek P, Mitchell JE, Berg KC, Peterson CB, Wonderlich SA, Walsh BT (2015) The eating disorder assessment for DSM-5 (EDA-5): Development and validation of a structured interview for feeding and eating disorders. Int J Eat Disord 48(5):452-63. doi: 10.1002/eat.22388

21. Jenkins PE, Luck A, Cardy J, Staniford J (2016) How useful is the DSM-5 severity indicator in bulimia nervosa? A clinical study including a measure of impairment. Psychiatry Res 246:366-369.

doi:10.1016/j.psychres.2016.10.011

22. World Health Organization (2000) Obesity: preventing and managing the global epidemic. Report of a WHO Consultation. Author, Geneva. 
23. Fairburn CG, Beglin SJ (2008) Eating Disorder Examination Questionnaire (EDE-Q 6.0). In: Fairburn CG (ed) Cognitive behaviour therapy and eating disorders. Guilford Press, New York, pp. 309-313.

24. Berg KC, Peterson CB, Frazier P, Crow SJ (2012) Psychometric evaluation of the eating disorder examination and eating disorder examinationquestionnaire: a systematic review of the literature. Int J Eat Disord 45:428438. doi:10.1002/eat.20931

25. Bohn K, Fairburn CG (2008) Clinical Impairment Assessment Questionnaire (CIA 3.0). In: Fairburn CG (ed) Cognitive behaviour therapy and eating disorders. Guilford Press, New York, pp. 315-317.

26. Jenkins PE (2013) Psychometric validation of the Clinical Impairment Assessment in a UK eating disorder service. Eat Behav 14:241-243. doi:10.1016/j.eatbeh.2012.12.001

27. Reas DL, Stedal K, Lindvall Dahlgren C, Rø $\varnothing(2016)$ Impairment due to eating disorder pathology: identifying the cut-off score on the Clinical Impairment Assessment in a clinical and community sample. Int $\mathrm{J}$ Eat Disord 49:635-638. doi:10.1002/eat.22517

28. Connell J, Barkham M, Stiles WB, Twigg E, Singleton N, Evans O, Miles JN (2007) Distribution of CORE-OM scores in a general population, clinical cutoff points and comparison with the CIS-R. Br J Psychiatry 190:69-74. doi:10.1192/bjp.bp.105.017657

29. Jenkins PE, Turner HM (2014) An investigation into the psychometric properties of the CORE-OM in patients with eating disorders. Counsel Psychother Res 14:102-110.doi:10.1080/14733145.2013.782057 
30. Fairburn CG (2008) Cognitive Behavior Therapy and Eating Disorders. Guilford Press, New York, NY.

31. Faul F, Erdfelder E, Lang A-G, Buchner A (2007) G*Power 3: a flexible statistical power analysis program for the social, behavioral, and biomedical sciences. Behav Res Methods 39:175-191. doi:10.3758/BF03193146

32. Mond JM, Hay PJ, Rodgers B, Owen C (2006) An update on the definition of "excessive exercise" in eating disorders research. Int J Eat Disord 39:147153. doi:10.1002/eat.20214

33. Mond JM, Hay PJ, Rodgers B, Owen C (2011) Mental health impairment associated with eating-disorder features in a community sample of women. $\mathrm{J}$ Ment Health 20:456-466. doi:10.3109/09638237.2011.577112

34. Mond JM, Rodgers B, Hay PJ, Darby A, Owen C, Baune BT, Kennedy RL (2007) Obesity and impairment in psychosocial functioning in women: the mediating role of eating disorder features. Obesity 15:2769-2779. doi:10.1038/oby.2007.329

35. Mond JM, Hay PJ, Rodgers B, Owen C (2006) Eating Disorder Examination Questionnaire (EDE-Q): norms for young adult women. Behav Res Ther 44:53-62. doi:10.1016/j.brat.2004.12.003

36. Mond JM, Hay PJ, Rodgers B, Owen C (2007) Recurrent binge eating with and without the "undue influence of weight or shape on self-evaluation": implications for the diagnosis of binge eating disorder. Behav Res Ther 45:929-938. doi:10.1016/j.brat.2006.08.011

37. Mitchison D, Mond J, Slewa-Younan S, Hay P (2013) Sex differences in health-related quality of life impairment associated with eating disorder 
features: a general population study. Int J Eat Disord 46:375-380.

doi:10.1002/eat.22097

38. Wagner AF, Stefano EC, Cicero DC, Latner JD, Mond JM (2016) Eating disorder features and quality of life: does gender matter? QualLife Res 25:2603-2610. doi:10.1007/s11136-016-1283-9

39. Carter JC, Aimé AA, Mills JS (2001) Assessment of bulimia nervosa: a comparison of interview and self-report questionnaire methods. Int J Eat Disord 30:187-192. doi:10.1002/eat.1071

40. Mond J, Hay P, Rodgers B, Owen C, Crosby R, Mitchell J (2006). Use of extreme weight control behaviors with and without binge eating in a community sample: Implications for the classification of bulimic-type eating disorders. Int J Eat Disord 39:294-302.

41. Hrabosky JI, Cash TF, Veale D, Neziroglu F, Soll EA, Garner DM, StrachanKinser M, Bakke B, Clauss LJ, Phillips KA (2009) Multidimensional body image comparisons among patients with eating disorders, body dysmorphic disorder, and clinical controls: a multisite study. Body Image 6:155-163. doi:10.1016/j.bodyim.2009.03.001

42. Fairburn CG, Cooper Z, Shafran R (2003) Cognitive behaviour therapy for eating disorders: a "transdiagnostic" theory and treatment. Behav Res Ther 41:509-528. doi:10.1016/s0005-7967(02)00088-8 